\title{
ARTICLE
}

\section{Five fathers' experience of an adult son sustaining a cervical spinal cord injury: an interpretative phenomenological analysis}

\author{
Kevin J Hartie and Jonathan A Smith
}

The paper presents an in-depth idiographic study exploring the experience of fathers who have an adult son with a cervical spinal cord injury $(\mathrm{SCl})$. Five participants were recruited and individual semi-structured interviews were conducted. The interviews were transcribed verbatim and analyzed using interpretative phenomenological analysis. Two superordinate themes are presented highlighting. First, the ongoing negative impact of their sons' injury on the participants' role as fathers'. This comprises the negative impact on emotions with guilt common for failing in their perceived role as a father. The dissonance experienced between wanting to help encourage their sons' independence. Concern experienced due to their sons altered life trajectory and anxiety because they would not be alive to protect their son in the future. Second, how participants cope and adjust to their son's SCl are presented. Comprising of how positive thinking, such as focusing on their son surviving the trauma and the influence of seeing their son cope well affects how participants cope. Also, reflecting on how the injury has changed their life helps participants, to an extent, make sense of the trauma. The results are discussed in relation to the relevant extant literature to give a unique perspective about how $\mathrm{SCl}$ impacts their perceived role as fathers and the struggle to cope and adjust to the trauma. Future research investigating the impact of $\mathrm{SCl}$ on the family is warranted to better understand the wider implications.

Spinal Cord Series and Cases (2016) 2, 16015; doi:10.1038/scsandc.2016.15; published online 7 July 2016

\section{INTRODUCTION}

Spinal cord injury $(\mathrm{SCl})$ is an insult to the spinal cord resulting in a change, either temporary or permanent, in its normal motor, sensory or autonomic function. $\mathrm{SCl}$ is described as one of the most devastating and traumatic type of neurological impairments an individual can face, having profound effects on both the injured person and their family members. ${ }^{1}$ Approximately 730 people experience a severe $\mathrm{SCl}$ each year in the UK, and the prevalence of those living with $\mathrm{SCl}$ is estimated to be in the region of 40000 persons. ${ }^{2}$ Although the annual incidence of $\mathrm{SCl}$ in the USA is estimated to be 12000 new cases each year with the number of people living with $\mathrm{SCl}$ in the USA ranging between 238000 and 332000 persons. $^{3}$ Injuries are most common in individuals aged $16-30$ years and the ratio of injured males to females is $4: 1$. The legacy of impairment following an $\mathrm{SCl}$ can often have far reaching implications for many aspects of an individual's life, disrupting established patterns of daily living. ${ }^{4}$ The severity of the injury and amount of paralysis the individual experiences depends on the level and completeness of the injury. Thus, a cervical injury can result in quadriplegia when the person sustains paralysis and lost sensation in all four limbs. Apart from the physical difficulties experienced, adjustment to $\mathrm{SCl}$ is often difficult and complex.

Many negative factors have been reported as hindering adjustment following the injury; these include, social isolation, unemployment, depression, pain and substance abuse, stigma and social isolation, ${ }^{5-7}$ causing a significant negative impact on the quality of life. ${ }^{8,9}$ Other research highlights that $\mathrm{SCl}$ causes a 'loss' of identity for the individual because they can no longer participate in certain activities or made to feel 'invisible' in social situations. $^{10}$ However, in contrast, despite the considerable evidence that individuals experience negative stressors, a growing body of literature provides compelling evidence of positive life changes in the midst of their traumatic experiences. Many individuals, in time, adjust to their circumstances and lead meaningful and purposeful lives. ${ }^{11}$

Although the majority of the research focuses on the individuals who sustained the injury, it is recognised the injury has wide reaching implications. A small number of qualitative studies have explored the wider impact of $\mathrm{SCl}$ beyond the person who sustained the injury. Angel and Buus ${ }^{12}$ conducted a longitudinal phenomenological hermeneutic study into partners' experiences of $\mathrm{SCl}$. Their experiences were understood as a trajectory with three distinct successive phases: first, to be harmed by the partner's injury; second, to find oneself on the outside of their partner's life; and third, to struggle for the injured partner and reestablishing life as a couple. The partner not only mourned the injured partner's loss but also their own loss. Because of their interwoven lives, the partners felt that the injured body was their body as well, and the pain and loss of the injured partner was their pain and loss, too. Many felt isolated during the rehabilitation period because they were not involved and informed by staff at the hospital about their partners care. Following discharge, many partners' struggled to re-establish their relationships. Taking on the caregiver role, with little or no support, left some feeling fatigued and exhausted. The difficulty the partner experiences was also highlighted by Dickson et al., ${ }^{13}$ who used interpretative phenomenological analysis (IPA) to investigate the experience of assuming the primary caregiver for a group of spouses, following $\mathrm{SCl}$. The paper highlights the post-injury shift in the relationship dynamic participants experience by adopting the role of a caregiver. For some, the loss of sexual intimacy and having to perform personal care task, such as washing and toileting, 
Table 1. Table of information for participants in fathers study

\begin{tabular}{|lcllccccc}
\hline Name & Age & Occupation & Relationship status & Number of children & Age of injured son & Years since injury & Level of injury & Living with son \\
\hline Ivan & 48 & Builder & Partner & 2 & 24 & 6 & C4/5 \\
Rick & 56 & Bricklayer & Married & 2 & 25 & 7 & No \\
Steve & 60 & Retired & Married & 3 & 32 & 8 & Yes \\
Ben & 61 & Retired & Married & 3 & 25 & 5 & C5 \\
Gary & 62 & Student & Widower & 2 & 30 & No & No \\
\hline
\end{tabular}

reduced their sexual desire for their partner. Some participants felt the bond of marriage was something they 'could not break', and were bound to the marriage by a sense of duty. However, in contrast, there were some that felt their relationships had become stronger as a result of the trauma they had shared. For many participants, assuming the caregiver role meant a sacrifice of their former identities and freedom. They felt invisible to other people and that their wellbeing became secondary to their partner's needs. Many lost their freedom and agency, unable to participate in the lives they once had, making them feel dissatisfied and resentful of their new identity.

There is as paucity of research investigating the impact of $\mathrm{SCl}$ on other family members. A novel study by Akhatar et al. ${ }^{14}$ used IPA to investigate children's experiences of living with a sibling with SCl. Participants highlighted how their life was interrupted by the injury to their sibling. Of particular distress for siblings, was the separation they experienced from their family during the rehabilitation period. The absence of their mother and injured sibling was difficult for some to cope with. They also highlighted how having a disabled sibling limits the activities the family participate in together. Most participants reported how they have to take on carer duties for their sibling with $\mathrm{SCl}$, as well as doing more chores around the house. Many reported how they do not share their thoughts, fears and worries with their parents. Internalizing these feelings contributed to a sense of sadness, guilt, isolation and depression for some participants. The culmination of these factors results in a struggle to assert their own, unique, sense of self and identity, separate from their injured sibling.

The research mentioned highlights the wide reaching impact $\mathrm{SCl}$ has beyond the individual who sustained it and that further qualitative research investigating the wider implications of $\mathrm{SCl}$ is warranted. The objective of this article to add to the small number of qualitative studies and offer a new perspective of the impact $\mathrm{SCl}$ has on family members by focusing on the experience of fathers who have an adult son with a cervical SCl. The study adopts IPA, ${ }^{15}$ taking an idiographic, phenomenological perspective that is concerned with the participant's subjective experience. The aim is to offer insights into what it is like for participants to have a certain experience; what it means to them and how they make sense of that experience, making it appropriate for exploring the wider implications of $\mathrm{SCl}$; and highlight 'what it is like' for fathers to experience their son sustaining an $\mathrm{SCl}$.

\section{METHODS}

\section{Sample}

Ethical approval was given by Birkbeck, University of London. Purposive sampling identified a homogenous group consisting of five participants who agreed to take part in the research. Participants were included if their son had sustained a cervical SCl between the ages 18 and 30 years and were between 5 and 15 years post injury. Potential participants were identified through a charity called Backup, an organisation that offers support to individuals and families following $\mathrm{SCl}$. Five fathers agreed to take part in the study-Table 1. The participants' names and occupation were changed to protect their anonymity.

\section{Materials and procedure}

Informed consent was given by participants before taking part in a face-toface interview in their own homes. An interview schedule was designed before the interview (Appendix A), the intention being to allow for an open-ended interview that maintained a balance between guiding, and being led by the participant during the interview. The schedule started with broad, general questions to allow participants to set the parameters of the topic, as well as building a sense of rapport. These questions focused on the present time, asking for example, 'what type of relationship do you have with your son?' and 'how do you feel your son is coping with his injury?' The schedule then moved on to more sensitive topics that could possibly evoke traumatic memories by asking questions about the past and the injury to their son, such as, 'can you tell me about your son's injury?' Also questions about the future were asked, for example, 'do you have any concerns about the future?' The inductive interview style adopted a process of reflecting and probing using prompts such as, 'how does this make you feel?' or 'tell me more about that?', for example. The interviews lasted $1 \mathrm{~h}$ on average and were recorded on a digital Dictaphone (Olympus, Southend-on-Sea, UK) and transcribed verbatim, while maintaining the participants' confidentiality.

\section{Analysis}

Transcripts were analyzed using IPA. ${ }^{15}$ IPA is a qualitative methodology that adopts an idiographic approach, which aims to understand how individuals make sense of their experiences. The phenomenological underpinning means the emphasis is on the experiential claims of the participants, and how individuals make sense of certain experiences within certain contexts is the main concern. However, IPA recognises that access to experience is both partial and complex, ${ }^{16}$ requiring an interpretative process between researcher and participant

The idiographic approach means each transcript is analyzed separately to look for themes that capture the participant's experience. Initially the transcripts are read and reread to immerse the researcher in the data before a detailed textual analysis of the data focusing on content, use of language and metaphor. The interpretative analysis affords the researcher an opportunity to be critical of the data, questioning the claims made by the participant and transforming the initial notes into more specific emerging themes by relating them to psychological concepts and theory. Emerging themes were then clustered into groups which captured the participants experience, documented and evidenced in a table with extracts from the interview transcript. This process was repeated for each participant to produce a table for each. The participants' tables were then analyzed further to see which recurrent themes connects the participants. A master table of themes for the group was produced representing how the participants' experiences converge and diverge for each theme. Themes which were reported by at least three out of the five participants were categorized as being recurrent with all present in the majority of themes. These themes clustered together to form the two superordinate themes 'Negative impact on role as father and Coping and adjusting to son's SCl'.

To aid validity the research is consistent with the criteria set out for what constitutes good IPA research. ${ }^{17}$ The paper has a clear focus with strong data derived from the interviews and is rigorous by providing extracts from at least half the participants as evidence for each theme. Extracts were selected to represent the depth and breadth of each theme to the reader by selecting quotes which demonstrate convergence and divergence, while the narrative elaborating on each theme is interpretive not purely descriptive. 


\section{RESULTS}

Negative impact on role as father

The first superordinate theme groups together a cluster of four themes-negative emotional impact, struggle to find optimal balance of helping, concern about son's life and anxiety about 'not being there' for son in the future-to explore how the experience of being a father to a son who sustains a $\mathrm{SCl}$, has a lasting disruption to the participants' sense of self as they struggle to fulfil their perceived fatherly role.

Negative emotional impact. For three participants-Steve, Rick and Ben-the negative emotional impact was expressed as feelings of guilt associated with the injury to their son. Although, the cause of their guilt is portrayed differently by the participants in the theme, the underlying reason for it seems to stem from their fatherly instinct to protect and help. For instance, Ben feels guilty that his other son witnessed the death of another patient while supporting his injured son in intensive care following his injury, in the following:

I feel tremendously guilty about that because (pauses) I felt that should have been me, he should never have witnessed that [...] that guilt (sniffs) guilt stays with me on that, although it-just one of those things. (sniffs)—(Ben: 4, 13-16)

In this case, it seems, the guilt Ben experiences is linked to his perceived failure to take the burden of his son's injury away from the other members of the family. He became very emotional and started crying as he reflected on the guilt he holds onto following this incident. Seemingly, his guilt is linked to his perceived failure to fulfil his role as a father, which in this instance, required him to protect his other son from the trauma of the injury. Although the guilt Ben experiences is in relation to a different son than the one who sustained the $\mathrm{SCl}$, it stems from his injury, and highlights the wide reaching impact of the injury on his perceived role as a father. For another participant, Steve, the guilt he experiences is linked to a feeling that he's, in some way, responsible for the injury to his son:

I'd introduced both of my sons to rugby, because I enjoy rugby so much, and the game that I love had caused this injury (Pauses) That makes me feel a bit low, that l'd done that-(Steve: 1, 15-18)

Steve introduced his son to the sport he was participating in when he sustained his $\mathrm{SCl}$. As a father, he wanted his sons to glean the same experiences and pleasure from rugby as him. However, there is a strong sense of guilt because he feels that he influenced his son to play rugby. The quote highlights the feeling of dissonance Steve has between rugby, and the injury to his son. There is a suggestion he feels guilty about still deriving pleasure from the sport that has caused so much heartache to himself and his family. Moreover, when he mentions, 'that I'd done that', the question is, how much responsibility he feels he has for the injury? Was rugby or Steve, responsible for the injury? What is evident is the detrimental impact of his influencing his son to play rugby, has on his sense of self. In a different way, the feelings of guilt Rick experiences is in relation to the amount of help and time he gives his son:

since the accident I tend to go more, do more with him. Interviewer: Why do you think that is?

Rick: (Pauses) I think like, it's guilt. I'm you know, I feel, uhh (pauses) that now he's not sort of able bodied (pauses) in a sense, I feel like I should (pauses) do more, you know, be there for him more-(Rick: 8, 3-5)
Rick reported that since his son's injury, he feels compelled to spend more time with him. When probed as to the reason for this, he conceded that he feels guilty that his son is now disabled and needs help with even the most basic tasks of daily living. The quote suggests Rick feels guilty that he is powerless to help his son in many ways. Ultimately, his son has to carry the burden of the injury and he attempts to assuage the guilt he experiences by spending more time with him. In this case, it seems that the guilt acts a catalyst for Rick to change his behavior and spend more time with his son.

Struggle to find optimal balance of helping. All the participants reported their struggle to find an optimal balance of help they give their son. For many of the participant, the struggle is in relation to the dissonance they experience between the natural parental desire to help their child, and not wanting to interfere with their life or limit their independence. In Steve's case, helping his son lets him feel involved with his son:

That helps being involved actually, doing things for him, doing a few things for him[...]l don't want to interfere too much because it's his life and he's got to lead it and we'll do certain things he wants us to do-(Steve: 7, 16-17)

Helping his son is helpful for Steve; however, his struggle in getting the balance correct is evident from the quote. He recognises that his son needs his independence, and does not want to interfere in his life. He takes his lead from his son as to how much assistance his son needs. Finding the optimal balance of helping is difficult however, because at times, this requires the participants to 'stand back' and watch their son struggle with certain tasks. For instance, Gary conveyed the difficulty he experiences watching his son struggle with certain tasks, in the following quote:

as a dad, caring loving dad, umm, I wanna do anything that I can do to make things (emphasizes) easier for Joe. So if it meant, um, intervening, doing something to make it quicker or easier for Joe, then of course, knee jerk reaction, that's what you do-(Gary: 5, 31-33)

Gary expresses how, as a father, he instinctively wants to help his son, Joe, when he sees him struggling with certain tasks. It is like a reflex, a 'knee jerk reaction' to want to help. However, Gary goes on to report how he has to struggle against his desire to help Joe, to allow his son to learn how to do these tasks for himself, and maximize his independence, in the following:

this is the only way forward and also struggling with-l just want to help him, I just want to make it easier for him-which of course is, the inner struggle that any parent will go through[...] everything is telling you that you want to do to help your child(Gary: 5, 34-39)

The conflict Gary experiences when resisting his parental instinct to help his son, is evident from the affecting quote above. Finding the optimal balance of helping, means, not helping, in some instances. He recognizes 'this is the only way forward' to allow his son to maximize his independence. However, standing back and watching his son struggle has a detrimental impact on his sense of self, because it flies in the face of what he believes his role of a father is. Other participants reported similar feelings, when having to watch their son struggle to carry out tasks. Indeed, Rick reported how not helping when he sees his son struggle with tasks important to his independence, such as feeding himself, makes him feel guilty for not assisting. For Ben, however, the struggle is reported in relation to his need to give his son more responsibility over his personal affairs, as he expressed the following: 
I am pulling back but, Jon had the position where I wouldn't even give him the option I would take, all the financial and all the issues, anything that was going to be stressful, off[...]but I don't think I'm doing him any favors because, he hasn't learnt the system [...]l am learning now and thinking I gotta off load this, he needs to know it, he's not a kid anymore, he's a twenty five year old man-(Ben: 11, 1-3)

In helping his son, Ben feels he has gone too far, meaning his son has not learnt how to manage his own affairs since his injury. There is a sense of dissonance, for Ben, between wanting to alleviate the stress his son is under and realising his son needs to take responsibility for himself. By helping too much, he feels he is doing more harm than good in the long term by making him less independent. However, you get the feeling, offloading the responsibility to his son is something he will find difficult to negotiate.

Concern about son's life. As fathers, the participants held certain expectations about the life their sons would have before $\mathrm{SCl}$. However, as a consequence of the injury, the trajectory of their son's life altered, leaving them with concerns about the new direction of their son's life.

For the participants, the sense of concern they experience is with regard to the expectations they held about the life their son would have had if not injured. This comes to the fore, for the participants, when comparisons are made between their son's preinjury life, as well as, his peers. For example, Ivan reflected on concerns he has about his son, in comparison to his other children or son's friends, who have been to university, and are now building careers, in the following extract:

I've got a concern yeah I'm definitely concerned, you know, 'cos I want to see Paul doing more things and have a bit more um, structure in his life-(Ivan: 11, 1-2)

Ivan's concern is centered on the perceived lack of direction his son has to his life. Because of the injury, certain expectations he had about his son, such as getting job, are yet to be fulfilled. He can see others of similar age to his son reaching certain milestones his son is yet to achieve. Consequently, this results in Ivan feeling concerned about his son, which, he reports elsewhere in the interview, is not the case for his daughter.

Seemingly, the participants' sense of concern is not only in relation to the present but also their future expectations about the trajectory of their sons' life. For example, Rick conveyed how he feels his son's life has been disrupted by his SCl and the concerns he has about the future, in the following:

he would have been, you know, a young man and gone to uni, get married, good job, look after himself, (hesitates)[...] umm, I just, I wouldn't want him, like, being stuck here on his own, you know, like, in his own little room like vegetating away[...]l worry, will he get married, things like that, it would be nice if, he did meet someone, who wanted to, you know, marry him for who he is, (pauses) see past the chair, the wheelchair and that an-and marry him for what he, because he's, a nice lad-(Rick: 7, 27-33)

For Rick, there was an expectation that his son would have got an education, career and found a partner, if he had not been injured. Instead there is a pernicious fear, in which he envisions a bleak and isolated future for his son. The feeling from the quote is Rick has low expectations about what he perceives is possible for disabled individuals. Coupled with this is a sense he perceives society in general stigmatises disabled individual's. Notice in the quote how he makes reference to his anxiety about his son being alone 'in his own little room, vegetating away', giving rise to the image of his son isolated from society. He goes on to expresses his hope that his son will one day get married. However, his perception of disability means he struggles to envisage a potential partner for his son, 'who can see past the wheelchair'. What is clear, is the sense of grief and loss Rick feels between the life he expected his son to have, and the one he has post $\mathrm{SCl}$, leaving him worried about what lies in store for his son in the future. Similarly, Gary expressed concern in relation to his son's ability to have children in the future:

if he wasn't able to have children, um, that is something that I would have to learn to live with um, that I would feel more concerned not for myself (quieter) not being a granddad or anything, l'd be more concerned about the effect that it would have on-on Joe and his partner-(Gary: 11, 12-15)

Gary reported how his concern is more about his son not becoming a father and the effect that will have on his son and partner, rather than his own desire to be a grandparent. Although, there is a sense from the quote he feels a sense of loss that he might not have grandchildren. He lowered his voice when he mentioned 'not being a granddad', possibly because he felt selfish considering his own needs in this case. Although, clearly, the main focus of his concern is his son, and how he will deal with the consequences, if he cannot have children in the future.

\section{Anxiety about 'not being there' for son in the future.}

Interviewer: I was going to ask about how you feel about the future?

Rick: (Sighs) Scared. Really scared, umm, that is, my biggest worry, that is, you know, when I'm gone, when I'm (pauses) dead and buried or whatever and me wife's dead and gone (pauses) leaving him on his own. It worries me (pauses) shitless. I'm scared, really scared. I-I think about that nearly every day, -him being left on his own[...] that is my biggest worry in life, that is, that is hitting the nail on the head. That worries me every day (pauses) not being there for him anymore-(Rick: 7, 16-25)

Beginning with Rick's powerful, and emotive quote, highlights an anxiety shared by all the participants. The worry Rick experiences about not being around to help his son in the future is palpable from the quote. As a father, he takes responsibility for protecting his son and has little trust that others will take on this role when he and his wife are no longer around. There is a sense from the quote that this is at the root to his concerns about his son when he expressed 'that is hitting the nail on the head'. He is prepared to do anything to protect his son, but time is against him, and the likelihood is he will die before his son. The impact this has on his sense of self is evident from the quote, when he expresses how, 'that worries me everyday'-ever present in his thoughts. This is a concern shared by several of the other participants. For example, Steve expressed:

Concerns are that obviously my wife or I, our health would fail and we couldn't help Mike as much as we'd like to-(Steve: 23, 10-16)

While in a similar way to Steve, Ben conveyed:

hang on a minute, we're not getting any younger, umm, there's going to be a time when Eve and I are not going not be about-(Ben: 11, 1-2)

Although their sons are adults, the participants feel that due to $\mathrm{SCl}$ they will always need their support in a way that is different from their other children. Most of the participants' sons are single 
and yet to form a long-term relationship. Possibly seeing their son in a settled relationship and with a family of their own will reduce some of the anxiety. However, there is a sense that they feel their son will never be fully independent. For many, this is due to their sons requiring carers to assist them with certain tasks of daily living, and concerns they have about their son developing a secondary health condition. Seemingly, the participants feel it's their role as fathers to keep a watchful eye over their son. However, they know the amount of time they will be able to do this for is limited, causing them to feel anxious about who will be watching over their son, when they no longer can.

\section{Coping and adjusting to son's SCl}

The second superordinate to emerge from the analysis clusters together the following themes: 'coping with positive thinking, positive influence of seeing son cope and reflection on change to life'-which highlight how the participants cope and adjust to their son's SCl.

Coping with positive thinking. For the participants, certain cognitive processes influence how they cope with their sons' injury. Many reported how they use positive thinking to help them cope. However, in contrast to the other fathers, Rick, expressed how he ruminates about the cause of the accident, and the negative influence this has on his ability to cope with his son's SCl.

Positive thinking was reported by the participants in several different contexts. At a broad level, some reflected on how their son had nearly died following the accident which caused the SCI and fortunate that their son had survived the injury. Indeed, Gary expressed how focusing on the reality of his son almost drowning enables him to focus on the positive aspects of the injury, in the following:

It made me realise quite early on how lucky we are, because um, Joe could have drowned, another thirty seconds later with his accident, he'd have drowned he'd be dead. Now his life [...] is more than worth living it's not even just a scrape through, worth living, it's as-as worthy of living had he not had the accident(Gary: 10, 3-7)

By focusing on how close his son came to dying, Gary is able to recognize he is fortunate that his son is still alive. There is a sense from the quote, that initially he had low expectations about what the quality of his son's life would be following the accident. However, he makes sense of the injury by appreciating that having a 'disabled' son, is preferable to a dead one. Quickly, he was able to focus on the positive aspects of his son's life, seeing it as comparable to the life he might have had, had he not been injured. Other participants reported that despite the difficulty they experience as a result of the injury, there are positives to be drawn on which help them cope. For example, Steve reported:

this is obviously the biggest trauma in my life. But even with small things or mistakes at work you've got to take positives out of things that go wrong-(Steve: 4, 21-24)

Evidently, Steve attempts to assuage the trauma-'the biggest trauma in my life'-experienced by his son's injury is by focusing on the positives that have come from the injury. Hence for Steve, this means he gets to spend more time with his son. Moreover, the quote highlights a certain mind-set that is shared by several of the participants, which acts almost like a default setting to help them cope with difficult experiences. In another example, Ben reported how this helps him cope with the cause of his son's injury: look forward and always, uh, on the positive side. Don't look back, what if Jon had decided 'how deep is this pool?' What if umm, you know, don't-don't do too many what if's? Just keep on the positive side-(Ben: 14, 9-12)

Seemingly, Ben uses this strategy to stop him ruminating about the past, and the cause of the injury to his son. However much he goes over the cause of the injury asking 'what if?' nothing changes, meaning he feels it's futile looking to the past. This was common for several of the participants, who equated positive thinking with 'looking forward' or 'focusing on the future'. It seems this strategy helps put a 'buffer' psychologically, between themselves and the trauma associated with the injury to their son.

However, the experience of one participant, Rick, diverges from the other fathers. In the following quote, he conveys the affect of ruminating about the cause of the injury to his son:

I still think of now is the person that caused the accident, you know, not even an apology (pauses) not even, you know, 'so sorry it happened.' That, that still bugs me today a-and it's horrible to think that (pauses) you know, to say I hope something happens to them, I do. I hope he dies an agonizing death (pauses) you know, 'cos I hate him so much-(Rick: 3, 4-5)

For Rick, blame for the injury to his son is attributed to a third party and his thoughts seem to be fixed on the cause of the injury. It is evident from the quote the pernicious impact of this on his sense of self. His desire for revenge leaves him with an ongoing sense of anger which, 'still bugs me to this day'.

Positive influence of seeing son cope. Key to all the fathers' ability to cope with their son's SCl, is how well they perceive their son to be coping with their disability. All the participants in the study reported that, currently, their son is coping well with their injury. In turn, this has a positive influence on how the fathers cope. However, several of the participants reflected on how this would be different if their son was struggling. For example, Ivan reported:

if obviously Paul (Son) was upset and, umm, feeling bad about it all the time and dwelling on it then (pauses) it would sort of put a cloud over everything else but because he's sort of reasonably, bright and sort of looking forward then, yeh definitely helped(Ivan: 6, 21-25)

Looking at the quote, there is a sense, Ivan looks to his son to gauge how to cope with the injury. He uses the metaphor 'put a cloud over everything', to express how seeing his son struggle to cope with the injury would have a negative influence on him. He goes on to mention that his son, Paul, is 'bright', which gives the impression that he is the sunshine, lighting the mood of the family. Echoing Ivan, Steve highlighted the positive influence seeing his son cope well has on himself and the rest of his family:

if he was not coping so well, it would put extra pressure on my wife and I and the rest of the family-(Steve: 4, 6-7)

For Steve, there is relief that his son is coping well with the injury. The positive influence this has on him and the rest of his family is evident from the quote. He mentions how the reverse would put 'extra pressure', on the family unit, suggesting a certain amount of pressure already exists. For many, seeing their son cope with their injury also serves as a source of pride and inspiration. They describe their son as 'fantastic' and 'able to deal with virtually anything', because of their ability to cope with the SCl. How their 
sons cope is attributed to their positive attitude by several of the participants. Ben expressed how his son's positive attitude is influential to how they both cope in the, following quote:

he is a positive lad and that helps no end. Umm, a-a-and in the last few years, uhh, I suppose only a couple of times has he, um, uh b-bottomed out, you know, a-a-and you feel worthless that you can't sort of help-(Ben: 2, 19-23)

Although Ben's son is coping well with his injury, he reflects on how he felt the times when his son has struggled to cope with his injury. The influence of seeing his son struggle is palpable in the quote. Seemingly, he feels it is his role to take the burden away from his son when he is experiencing difficulty coping, and being unable to leaves him feeling 'worthless', when he cannot help.

Reflection on change to life. The following theme demonstrates how participants reflected on the change the injury has had to their life, and the impact of this on how they cope and adjust to their son's injury. For some this is in relation to the way they view the environment and the world around them. For instance, Ivan reported how the injury to his son has changed the way he views life in the following quote:

looking at, life in a different way cos suddenly you think about it, you know, pushing a wheelchair it's, it's things like, is it accessible? and things like that so you just gotta think and plan things through more thoroughly I guess (pauses) You can't get in the car and go off you gotta think-(Ivan: 3, 16-21)

For Ivan, the injury to his son means he has to plan thing a lot more. To an extent, he now views the world through his son's eyes, checking if there is appropriate wheelchair access when going to places. The quote goes on to highlight how the accessibility of the social environment not only effects the wheelchair user but also those supporting them. Thus, coping with the environment requires planning which reduces the spontaneity Ivan had before the injury to, 'get in the car and go off'. Other participants reflected on how they are now more aware of issues related to disability and the challenges disabled individuals face in society. For example, Rick conveyed how the injury to his son has changed his view of disability:

I see things in a big different light. You know, people in wheelchairs now I hold a lot more respect for-(Rick: 6, 35-38)

The quote from Rick highlights the adjustment he has made to the way he views disabled people in society.

Having direct experience of disability has opened his eyes to the challenges associated with being a wheelchair user. He now has more 'respect' for wheelchair users and compassion for their plight. For many, the $\mathrm{SCl}$ to their son was their first exposure to disability. It appears that the injury to their son has challenged the preconceptions some of the participants held about disability. It is possible adjusting their perception about disability, facilitates how the fathers cope with the injury to their son. With no option to change the $\mathrm{SCl}$ to their son, adjusting how they think about disability and the status of disabled individuals in society means they can view the injury in a more favourable light.

Several participants reflected on a broader, existential change they have experienced following the injury to their son. For example, Ben expressed how he has changed due to his son's $\mathrm{SCl}$, in the following:

Has it changed me? I-I discovered my faith, has changed me, has made me more al-a calm person, uhh, I think that Jon's (son) trauma has put (emphasizes) everything into perspective-(Ben: $13,27-28)$

The injury to his son has challenged the taken for granted assumptions Ben held about reality and changed him as a person. Evidently, he has a different perspective on what is now important in life looking to religion to help him cope with his son's injury. In a sense, this helps him find meaning to his existence by giving him answers to questions that are beyond science and medicine.

By taking into account the changed reality of his life circumstances and the inherent complexity, unpredictability and fragility of the human condition, he has adapted his beliefs to make sense of and cope with the trauma he experienced and possible challenges in the future.

\section{DISCUSSION}

The participants' accounts showed the negative impact of the injury on their perceived role as fathers and the derogatory influence of this on their identity and sense of self continuing in the present. A person's identity and sense of self are formed through social relations and can be defined as the person we think we are. It is 'the self we know'. ${ }^{16}$ Illness-in this case SCl-may challenge an individual's sense of self and identity, forcing an alteration and renegotiation of its elements. ${ }^{17}$

In the first instance, the research demonstrates the negative emotional impact of this for the fathers. The overriding negative emotion for some participants was one of guilt. Guilt was demonstrated in several ways by the participants, but was linked to their perceived failure to fulfil their role as fathers. According to Hoffman, ${ }^{18}$ when we see another person suffering, it can also cause us pain. This constitutes our powerful system of empathy, which leads to our thinking that we should do something to relieve the suffering of others. If we cannot help another, or fail in our efforts, we experience feelings of guilt. The claim is this emphatic response is stronger in close relationships, motivating relationship enhancing patterns of behavior. However, the research highlights the feeling of helplessness the participants experience when faced with the empathy they feel for their sons, which leaves them feeling guilty they cannot do more. The guilt some of the fathers experience is linked to a perceived harm they caused their son. The guilt experienced seems to be linked not only to the harm they feel they have caused but also how they think their son and possibly others judge them. Miller and Abraham ${ }^{19}$ noted that guilt depended on a concurrence of self judgement and the other person's judgement. However, the present research highlights how the negative emotions the participants experience is not an interactive product of self judgment and judgement by their son, because they have not discussed these emotions with their son. What is evident is these negative emotions are linked to their role as fathers and the detrimental impact they have on their sense of self. The present study demonstrates how the fathers struggle with their role when it comes to finding the optimal balance of helping their son. The tension they experience between their fatherly instinct of wanting to help and their desire to see their son as independent is palpable. Seemingly, for some getting the optimal balance of helping means they have to hold themselves back and watch their son struggle. The internal struggle the fathers experience relates to Festinger ${ }^{20}$ theory of cognitive dissonance which focuses on how humans strive for internal consistency. When dissonance is experienced, individuals can become psychologically uncomfortable and motivated to reduce the dissonance. Evidently for the participants in the present study, the dissonance they experience between, wanting to help and holding back, has a negative impact. Their desire is to reduce the dissonance they experience by helping, but know it is not best for the future interests of their 
son. This has a negative impact on their sense of self with some feeling guilty for failing to fulfil their parental role.

As consequence of the injury their sons life trajectory has been altered, meaning certain expectations they held about their lives have been disrupted. Evidently, this is a source of anxiety for both the present and the future. The fathers' experiences draw parallels with parents that have caregiver responsibilities for adults with disabilities, who must cope with feelings of loss and grief that their child will not experience a 'normal' life. ${ }^{21}$ This supports the literature which reports parents suffer a response to grief and loss at the diagnosis of a serious disability, illness or injury to child. ${ }^{22,23}$ Rando ${ }^{24}$ proposes that parents experience grief in three stages. An 'avoidance phase' in the early stages of grief, in which numbness and shock pervade their existence. The 'confrontation stage' when the individual feels intense emotion as they begin to face the loss. Finally, the 'accommodation stage' where the person begins to face the loss.

For the participants, seeing their son having a career and in a relationship with a life partner, for example, will mitigate some of the anxiety they feel about their loss. However, they see it as their fatherly role to protect their son while acknowledging the time they have to do this is limited. This feeds into the anxiety they experience about their own mortality and not being around to help their son in the future. Possibly interventions geared towards helping the individual with $\mathrm{SCl}$ reach an optimal level of independence, such as training about how to effectively organise care, may reduce some of their stress. However, the research highlights the in-depth struggle the fathers experience and offers their hitherto untold story.

Although the negative impact of the injury on the participants is clear, they reported how they cope and adjust, over time, to the injury to their son. Many of the participants reported how they cope with their son's injury by adopting positive thinking to help them adjust. This strategy is used by the participants to successfully reappraise their situation. This echoes research reporting that positive perceptions function as strategies that help families adapt to, or cope, with the experiences of disability to a child. ${ }^{25,26}$ For many of the fathers in the present study, adopting this strategy counteracts the negative ruminative cognitions they might otherwise experience. They concede they have no control to change the injury to their son; however, they have control about how they think about it. Although the struggle the fathers experience is apparent, many of the participants have reached a level of acceptance about their son's disability. Acceptance is related to more positive adjustment and improved mental health outcomes amongst adult carers. ${ }^{27}$ Although the participants in this study are not carers, as fathers they feel they have a responsibility for their son. Seemingly, acceptance and adjustment is mediated by how well they perceive their son to be coping. The influence of their son is important to how well they cope. This reflects the research investigating how families cope with childhood chronic illness conditions. ${ }^{28}$ However, the present study reveals how the fathers experience a sense of fragility in relation to their son's coping, which makes them feel helpless when their son struggles to cope. Seemingly the participants have adapted the way they view the world to fit their new circumstances. Taylor ${ }^{29}$ proposes a theory of cognitive adaption where individuals use a number of cognitive strategies to counteract the negative impact of distress on wellbeing. These include a search for meaning where the individual tries to achieve or maintain an optimistic attitude toward the event or towards life in general, an attempt to regain mastery over the event or over one's life in general, and a restoration of self-esteem. To an extent, this framework maps well to some of the fathers' experiences offering a stress and coping level explanation of the participants' cognitive processes helping them make sense of and adjust to the trauma of their son's SCl. This offers an opportunity for interventions that allow the individual to make sense of the trauma within the context of their lives.

\section{CONCLUSION}

In conclusion, this paper presents two superordinate themes to highlight experiencing an adult son with $\mathrm{SCl}$. First, the ongoing negative impact of their sons' injury on the 'participants' role as fathers'. This comprises the negative impact on emotions with guilt common for failing in their perceived role as a father. The dissonance experienced between wanting to help and encouraging their sons' independence. Concern experienced due to their sons altered life trajectory and anxiety because they would not be alive to protect their son in the future. Second, how participants cope and adjust to their son's SCl. Comprising of how positive thinking, such as focusing on their son surviving the trauma; and the influence of seeing their son cope well affects how participants cope. Also, reflecting on how the injury has changed their life helps participants, to an extent, make sense of the trauma.

\section{REFLECTIONS}

The findings of this study are from a small sample and are not seeking to make generalizations that others in a similar situation will share the same experiences. However, using IPA prioritizes the participants' idiographic experiences meaning they all powerfully talked about the injury to their son in similar ways, which can allow the reader to think about how these findings are illuminating in a wider context. It is possible a selection bias took place with recruitment with those agreeing to take part being better adjusted to their son's injury. However, the participants spoke candidly about their difficulties and the challenges they face. It would be useful to conduct a subsequent study looking at different groups of family members and compare the findings to the results in this study. Also, conducting a family study from the same family could provide interesting results.

\section{COMPETING INTERESTS}

The authors declare no conflict of interest.

\section{REFERENCES}

1 Gill M. Psychosocial implications of spinal cord injury. Crit Care Nurs Q 1999; 22: $1-7$.

2 Dean RE, Kennedy P. Measuring appraisals following acquired spinal cord injury: a preliminary psychometric analysis of the appraisals of disability. Rehabil Psychol 2009; 54: 222-231.

3 Jain N, Ayers G, Peterson E, Harris M, Morse L, O'Connor K et al. Traumatic spinal cord injury in the United States, 1993-2012. J Am Med Assoc 2015; 313: 2236-2234.

4 Osteraker AL, Levi R. Indicators of psychological distress in post-acute spinal cord injured individuals. Spinal Cord 2005; 43: 223-229.

5 Craig A, Tran Y, Lovas J, Middleton J. Spinal cord injury and its association with negative psychological states. Int J Psychosoc Rehabil 2008; 12: 115-121.

6 Turner JB, Turner RJ. Physical disability, unemployment, and mental health. Rehabil Psychol 2004; 49: 241-249.

7 Belciug MP. Coping responses in patients with spinal cord injury and adjustment difficulties. Int J Rehabil Res 2001; 24: 157-159.

8 Mukai A, Costa J. The effect of modafinil on self-esteem in spinal cord injury patients. Arch Phys Med Rehabil 2005; 86: 1887-1889.

9 Phelps J, Albo M, Dunn K, Joseph A. Spinal cord injury in married or partnered men: activities, function, needs, and predictors of sexual adjustment. Arch Sex Behav 2001; 30: 591-602.

10 Dickson A, Allan D, O'Carroll R. Biographical disruption and the experience of loss following a spinal cord injury: an interpretative phenomenological analysis. Psychol Health 2007; 23: 407-425.

11 Chun S, Lee Y. The experience of posttraumatic growth for people with SCl. Qual Health Res 2008; 18: 877-890. 
12 Angel S, Buus N. The experience of being a partner to a spinal cord injured person: a phenomenological-hermeneutic study. Int J Qual Stud Health Well-being 2011; 6: 1.

13 Dickson A, O'Brien G, Ward R, Flowers P, Allan D, O'Carroll R. Adjustment and coping in spousal caregivers following a traumatic spinal cord injury: an interpretative phenomenological analysis. J Health Psychol 2012; 17: 247-257.

14 Akhtar M, Kennedy P, Webster G, Graham A. What about us? Children's experiences of living with a sibling with spinal cord injury. J Paediatr Rehabil Med 2012; 5: 301-313.

15 Smith JA, Flowers P, Larkin M. Interpretative Phenomenological Analysis: Theory, Method, and Research. Sage: London, 2009.

16 Christiansen $\mathrm{CH}$. Defining lives: occupation as identity: an essay on competence, coherence, and the creation of meaning. Am J Occup Ther 1999; 53: 547-558.

17 Charmaz K. Good Days, Bad Days: The Self in Chronic Illness and Time. Rutgers University Press: New Brunswick, NJ, 1997.

18 Hoffman ML. Development of prosocial motivation: empathy and guilt. In: Eisenberg-Berg N (ed.). Development of Prosocial Behaviour. Academic Press: New York, 1982.

19 Millar K, Abraham T. Deceptive behaviour in social relationships: a consequence of violated expectations. J Psychol 1988; 122: 263-273.
20 Festinger L. Cognitive dissonance. Sci Am 1962; 207: 93-107.

21 Greenberg JS, Seltzer MM, Greenley JR. Aging parents of adults with disabilities: The gratifications and frustrations of later life caregiving. Gerontologist 1993; 33: 542-550.

22 Fraley A. Chronic sorrow: a parental response. J Pediatr Nurs 1990; 5: 268-273.

23 Rolland JS. Anticipatory loss: a family systems developmental framework. Fam Process 1990; 29: 229-244.

24 Rando TA. Treatment of Complicated Mourning. Research Press: Champaign, IL, 1993.

25 Hastings $\mathrm{R}$, Taunt $\mathrm{H}$. Positive perceptions in families of children with developmental disabilities. Am J Ment Retard 2002; 107: 329-333.

26 Summers J, Behr SK, Turnbull A. Positive adaptation and coping strengths of families who have children with disabilities. In: Singer G, Irvin L (eds). Support for Caregiving Families: Enabling Positive Adaption to Disability. Brooks: Baltimore MD, 1988, pp 27-40.

27 Pruchno RA, Resch NL. Husbands and wives as caregivers: antecedents of depression and burden. Gerontologist 1989; 29: 159-165.

28 Cohen M. Families coping with childhood chronic illness: a research review. Fam Syst Health 1999; 17: 149-164.

29 Taylor SE. Adjustment to threatening events: a theory of cognitive adaptation. Am Psychol 1983; 38: 1161-1173.

\section{APPENDIX A}

\section{Present time}

1. What type of relationship do you have with your son?

-Do you see each other often

-Has the relationship changed post SCI

2. How do you feel your son is coping with his injury?

-Does this impact how you feel

-What, if anything, helps

3. How are you coping with your son's injury?

- What helps you cope

-What aspects are most difficult to cope with

Has the SCI to your son changed you?

-If yes how

\section{Past/injury}

4. Can you tell me about your son's injury?

-How did you feel at this time

-Did you receive support

-What, if anything, would have helped you

5. What impact did the injury have on you at this time?

-How did you feel

-Has this changed

6. What impact did the injury have on other family members?

-How did this make you feel

7. How did other people react to your son's injury?

-How did this make you feel

\section{Future}

8. How do you feel about the future?

-Has the injury changed how you see the future

-If yes in what way

9. Has the injury to your relative changed how you see the future?

-If yes in what way

10. Do you have any concerns about the future?

-If yes what are they

11. What if anything would you say to somebody experiencing a similar situation as you who asks

for your advice? 